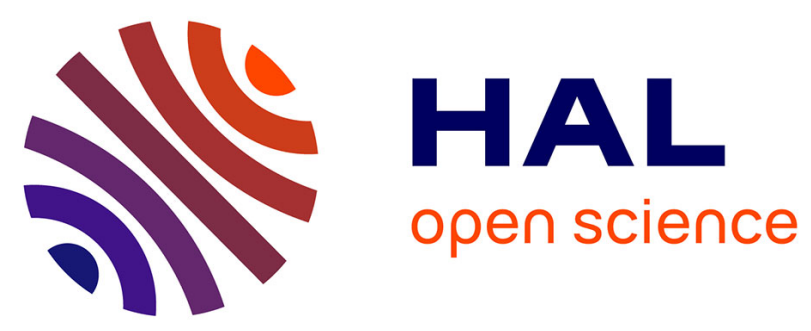

\title{
Comparison of fluorescence excitation modes for CdsSe semi-conductor quantum dots used in medical research
}

Y. Kuzishchin, I. Martynov, E. Osipov, P. Samokhvalov, A. Chistyakov, I. Nabiev

\section{- To cite this version:}

Y. Kuzishchin, I. Martynov, E. Osipov, P. Samokhvalov, A. Chistyakov, et al.. Comparison of fluorescence excitation modes for CdsSe semi-conductor quantum dots used in medical research. Bulletin of Russian State Medical University, 2018, 4, 10.24075/brsmu.2018.050 . hal-03026849

\section{HAL Id: hal-03026849 \\ https://hal.science/hal-03026849}

Submitted on 3 Dec 2020

HAL is a multi-disciplinary open access archive for the deposit and dissemination of scientific research documents, whether they are published or not. The documents may come from teaching and research institutions in France or abroad, or from public or private research centers.
L'archive ouverte pluridisciplinaire HAL, est destinée au dépôt et à la diffusion de documents scientifiques de niveau recherche, publiés ou non, émanant des établissements d'enseignement et de recherche français ou étrangers, des laboratoires publics ou privés. 


\title{
COMPARISON OF FLUORESCENCE EXCITATION MODES FOR CDSE SEMI-CONDUCTOR QUANTUM DOTS USED IN MEDICAL RESEARCH
}

Kuzishchin YA ${ }^{1 凶}$, Martynov IL ${ }^{1}$, Osipov EV ${ }^{1}$, Samokhvalov PS ${ }^{2}$, Chistyakov AA ${ }^{1}$, Nabiev $I^{2}$

\author{
Department of Physics of Micro- and Nanosystems, \\ National Research Nuclear University MEPhl, Moscow \\ ${ }^{2}$ Laboratory of Nano-Bioengineering,
}

National Research Nuclear University MEPhl, Moscow

Fluorescence spectroscopy is a powerful tool used in applied biological and medical research. Colloid semi-conductor quantum dots are promising fluorescent tags for simultaneous detection of different biopathogens. The techniques employing these tags can be improved by selecting the optimal modes for signal excitation and detection. The aim of the present work was to derive a mathematical expression to describe the signal-to-noise ratios in the pulsed and modulated excitation modes. Below, we compare these two modes of fluorescence excitation in ultralow quantities of quantum dots. We demonstrate that modulated excitation should be preferred for CdSe/ZnS quantum dots given that signal accumulation time is over $100 \mathrm{mc}$ and the photosensor is exposed to background light of $>1 \mu \mathrm{W}$.

Keywords: quantum dots, CdSe/ZnS, luminescence, excitation, photodetection

Funding: this work was supported by the Federal Target Program The National System for Chemical and Biological Security of the Russian Federation (20152020) and carried out under the state contract No. K-27-HИP/146-2 dated December 28, 2015.

$\triangle$ Correspondence should be addressed: Yuri A. Kuzishchin

Kashirskoe shosse, 31, Moscow, 115409; yriy.kuzishchin@gmail.com

Received: 29.07.2018 Accepted: 25.08.2018

DOI: $10.24075 /$ brsmu.2018.050

\section{СРАВНЕНИЕ РЕЖИМОВ ВОЗБУЖДЕНИЯ ФЛУОРЕСЦЕНЦИИ ПОЛУПРОВОДНИКОВЫХ КВАНТОВЫХ ТОЧЕК НА ОСНОВЕ СЕЛЕНИДА КАДМИЯ ДЛЯ БИОМЕДИЦИНСКИХ ПРИЛОЖЕНИЙ}

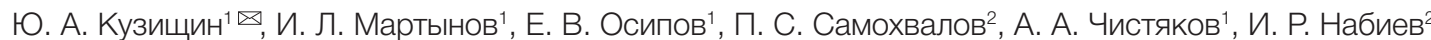

\author{
Кафедра физики микро- и наносистем, \\ Национальный исследовательский ядерный университет «МИФИ» (Московский инженерно-сризический институт), Москва \\ 2 Лаборатория нано-бионженерии, \\ Национальный исследовательский ядерный университет «МИФИ» (Московский инженерно-сизический институт), Москва
}

\begin{abstract}
В настоящее время, фрлуоресцентная спектроскопия - это мощный инструмент, используемый в биологических и медицинских прикладных исследованиях. Одним из перспективных типов люминесцентных меток для одновременного обнаружения различных биологических агентов в одной пробе являются коллоидные полупроводниковые квантовые точки. Важным направлением совершенствования методики их применения является подбор оптимального режима возбуждения и регистрации флуоресцентного сигнала. Таким образом, целью настоящей работы было получение математического выражения для оценки отношения сигнал/шум в случае импульсного и модуляциоонго режимов возбуждения. Представлены результаты теоретического сравнения данных режимов возбуждения для регистрации флуоресцентного сигнала от ультра-малых количеств квантовых точек. Показано, что в случае применения квантовых точек CdSe/ZnS в условиях фоновой засветки с мощностью свыше 1 мкВт и временем накопления полезного сигнала свыше 100 мс для достижения высокой обнаружительной способности предпочтительнее использовать модуляционный режим возбуждения.
\end{abstract}

Ключевые слова: квантовые точки, CdSe/ZnS, люминесценция, возбуждение, фотодетекция

Финансирование: исследование поддержано Министерством здравоохранения Российской Федерации, в рамках Федеральной целевой программь «Национальная система химической и биологической безопасности Российской Федерации (2015-2020 годы)», государственный контракт К-27НИР/146-2 от 28.12 .15

$\triangle$ Для корреспонденции: Юрий Александрович Кузищин

Каширское ш., д. 31, г. Москва, 115409; yriy.kuzishchin@gmail.com

Статья получена: 29.07.2018 Статья принята к печати: 25.08.2018

DOI: $10.24075 /$ vrgmu.2018.050

Today, fluorescence-based analytical techniques are widely used in applied biological and medical research to study protein structures [1-3], diagnose cancer [4-8] and autoimmune disorders [9], detect and classify biopathogens and toxins [10]. The majority of these techniques rely on fluorescence tags, among which semi-conductor quantum dots hold the highest potential [8, 11-13]. Unlike conventional organic dyes, quantum dots have broad absorption spectra [14, 15], exhibit high quantum yield [16] and record-breaking photostability [17]. Besides, the wavelength of the fluorescence emitted from quantum dots depends on their size, so one can «tune» the fluorescence spectra by varying the size of nanocrystals $[16,18]$.

Sometimes, as is the case with detecting low pathogen concentrations or screening for cancer and autoimmune 
disorders, it is necessary to record ultralow-intensity fluorescence [10]. Indeed, the best state-of-the-art photosensors sensitive to the visible light spectrum are capable of detecting single photons [10]. Such devices, however, only operate at very low temperatures $[19,20]$ and are ultrasensitive to background light [20]. These factors combined with high costs limit the use of photodetectors to specific laboratory equipment or commercial premium-quality machines [21-25]. Still, applied research cannot do without highly sensitive, small, cheap, backgroundnoise-resistant photodetectors for fluorescence-based assays involving multiple measurements of the same type.

Such photodetectors can be constructed from standard silicon PIN photodiodes. To reduce background light interfering with their performance, pulsed [26, 27] and modulated [28-30] excitation modes can be used for luminophore excitation. In the first approach, luminescence induced by pulsed excitation is detected over a short time interval comparable to the excited-state lifetime of the luminophore. If the intensity of the excitation pulse is chosen properly, the amplitude peak of the luminescence signal will significantly exceed the level of background light. This approach, however, has a drawback: it relies on the use of broadband photodetectors, broadband recording units and expensive laser sources of excitation radiation with a pulse duration ranging from $10 \mathrm{~ns}$ to tens of picoseconds, depending on the selected fluorophore.

In the second approach, the effect of background light is neutralized by reaching a high modulation frequency of excitation light that exceeds a typical fluctuation frequency of background light. Usually, the modulation frequency falls within a range of 10 to $100 \mathrm{kHz}$ [31, 32]. By applying the Fourier transform at the modulation frequency during signal processing, one can isolate and discard the signal resulting from low-frequency power fluctuations of background light.

To create a photosensor exploiting the principle of modulated excitation, narrowband or lock-in amplifiers, the Fourier transform of the emitted luminescence signal or their combination are employed [31, 32]. Each of these approaches has its own specifics. Although the use of a broadband amplifier necessitates a broad dynamic range and a good ADC (analog-to-digital converter) resolution for the Fourier transform to be applied, the latter is instrumental in eliciting a plethora of information about the recorded signal as possible. Narrowband amplifiers do not impose such strict requirements on the ADC but their architecture is more complex.

On the whole, the technique based on the modulation of excitation light requires a simpler laser source than the pulsedbased one. Still, it is not perfect: one of the most obvious downsides to it is long signal accumulation time not needed for pulsed excitation.

Considering the above said, the optimal choice of a technique for detecting low-intensity luminescence is determined by the photo- and physical properties of the selected luminophore and the level of background light. Devices for luminescence analysis must be fast, cheap and have low power consumption.

The aim of this work was to carry out a comprehensive comparison of techniques exploiting pulsed and modulated signals to excite low-intensity luminescence in the visible part of the light spectrum and detect it using PIN photodiode photosensors. The average power of excitation light was selected as a reference condition. We hope that the obtained data will aid in selecting the optimal system for a luminescence assay based on the excited-state lifetime of the luminophore and the level of background light. In this work we also talk about the choice of optimal modulation frequency of excitation light.

\section{METHODS}

In this section we derive mathematical expressions to describe the signal-to-noise ratio using a standard noise model, write them in a convenient form for further comparison and use them for the analysis of different fluorophore excitation modes. The average power of excitation light was selected as a reference condition allowing us to compare the pulsed and modulated excitation modes.

The output of the majority of $\mathrm{Si}$ PIN photodiode photosensors is voltage [33-36], whereas the photodiode itself is a source of current [37]. To convert current to voltage, such photodetectors are equipped with a transimpedance amplifier [38] set up for a particular task.

The main characteristics of a transimpedance amplifier are transimpedance resistance $R_{\mathrm{T}}$ and the upper bound frequency $f_{\mathrm{p}}$. The following statement is true for the signal with a frequency below $f_{\mathrm{p}}$ :

$$
U_{\mathrm{s}}=P_{\mathrm{s}} \cdot S \cdot R_{T},
$$

where $U_{s}$ is the output voltage, $P_{s}$ is the power of the fluorescence signal, $S$ is the sensitivity of the photodiode. The noise of the amplifier can be described in terms of the output voltage noise density of the amplifier $u_{n a}$. However, in practice NEP (the noise equivalent power of the optical signal) is often used for this purpose [37]:

$$
N E P=\frac{u_{\mathrm{na}}}{R_{\mathrm{T}} \cdot S}\left[\frac{W}{\sqrt{H z}}\right]
$$

Clearly, both NEP and the detection threshold of the photosensor are directly dependent on the noise characteristics of the amplifier and the operating mode.

Of note, the noise of a multistage amplifier is determined by the noise of the first stage [39]; the subsequent stages only proportionally increase the amplitude of both signal and noise and do not affect their ratio. This phenomenon allows us to use a single-stage amplifier as a model for analyzing noise characteristics. In transimpedance amplifiers the primary source of noise is the thermal noise of feedback resistance $R_{\mathrm{f}}$ which corresponds to transimpedance resistance $R_{T}$. Using the standard equation for thermal noise [40], one can write:

$$
N E P=\frac{1}{S} \cdot \sqrt{\frac{4 \mathrm{kT}}{R_{\mathrm{T}}}} \sim \frac{1}{\sqrt{R_{\mathrm{T}}}}, \text { (2) }
$$

where $k$ is the Boltzmann constant and $T$ is resistance temperature.

From the expression (2) we can deduce that an increase in feedback resistance improves noise characteristics of the photosensor, but because of the parasitic capacitance $C_{p}$ of the photodiode [37] the upper bound frequency $f_{p}$ decreases. Considering the relationship between $R_{T}$ and $C_{p}$, the NEP equation can be rewritten as follows:

$$
N E P=\frac{1}{S} \cdot \sqrt{8 \pi \kappa \top C_{p} f_{p}}
$$

The equation (3) means that the simplest way to detect an ultralow-intensity fluorescence signal is to continuously excite the studied sample and use a photosensor equipped with a direct current amplifier. This approach, however, is hardly ever implemented because of the sources of additional low-frequency noise $\triangle \operatorname{NEP}(f)$, such as flicker noise $[29,40,41]$, popcorn noise [40] and power fluctuations of external light sources [42-45]. At frequencies below $\sim 1 \mathrm{kHz}$, the contribution of these noise sources can considerably exceed thermal noise density and outweigh the advantages of a low-frequency photosensor [29, 
46]. Therefore, pulsed and modulated excitation modes are used instead, reducing the effect of additional noise sources [29]. Each of these approaches, however, has its own specifics.

For a broadband amplifier unexposed to background light and a signal induced by modulated excitation, the signal-tonoise ratio can be described by the following equation:

$S / N=\frac{P_{\text {lum }}}{P_{n}}=P_{\text {lum }}>\cdot 2 /\left(\int_{0} f m\left(\frac{8 \pi \kappa \top C_{p} f_{p}}{S^{2}}+\Delta \operatorname{NEP}^{2}(f)\right) d f\right)^{0.5}$

where $<P_{\text {lum }}>$ is the average power of the fluorescence signal, $P_{n}$ is the noise power, $f_{m}$ is the modulation frequency of excitation light. Presumably, the inverse duty ratio of excitation pulses equals 2 and the upper bound frequency of the amplifier fp equals the modulation frequency or slightly exceeds it.

At the same time, the photosensor operating in the modulated excitation mode can only have a narrow gain bandwidth $\Delta f_{\mathrm{p}}$ near the modulation frequency $f_{\mathrm{p}}$. So, to use modulated excitation, physical or programmable lock-in amplification [32], narrowband amplifiers [47] or filters [47] are required; alternatively, multiple measurements can be taken to average the signal [47]. These measures can help to avoid the contribution of $\triangle \operatorname{NEP}(f)$ to the total noise. If $f_{m}=n \cdot \Delta f p$, where $n$ represents the number of periods needed to average the signal, a photodetector with a narrowband amplifier can be described by the following equation:

$$
S / N=\frac{P_{\text {lum }}}{P_{\mathrm{n}}}=\frac{<P_{\text {lum }}>\cdot S \cdot \sqrt{n}}{f_{\mathrm{m}} \sqrt{2 \pi \kappa T C_{\mathrm{p}}}}=\frac{<P_{\text {lum }}>\cdot S}{\Delta f_{\mathrm{p}} \sqrt{2 \pi \kappa T C_{\mathrm{p}} n}},
$$

Another challenge of this approach is the choice of an optimal modulation frequency of excitation light. From (5) it is clear that one should use the lowest frequency possible allowed by the operational speed of the device. At frequencies below $\sim 1 \mathrm{kHz}$ the contribution of additional noises increases, rendering work in this mode useless. The presence of background light necessitates additional analysis with due account of the spectral density of external light fluctuations at various frequencies.

The pulsed excitation mode relies on the phenomenon of the peak power of the fluorescence signal $P_{\text {lum }}=\left\langle P_{\text {lum }}\right\rangle \cdot d$,
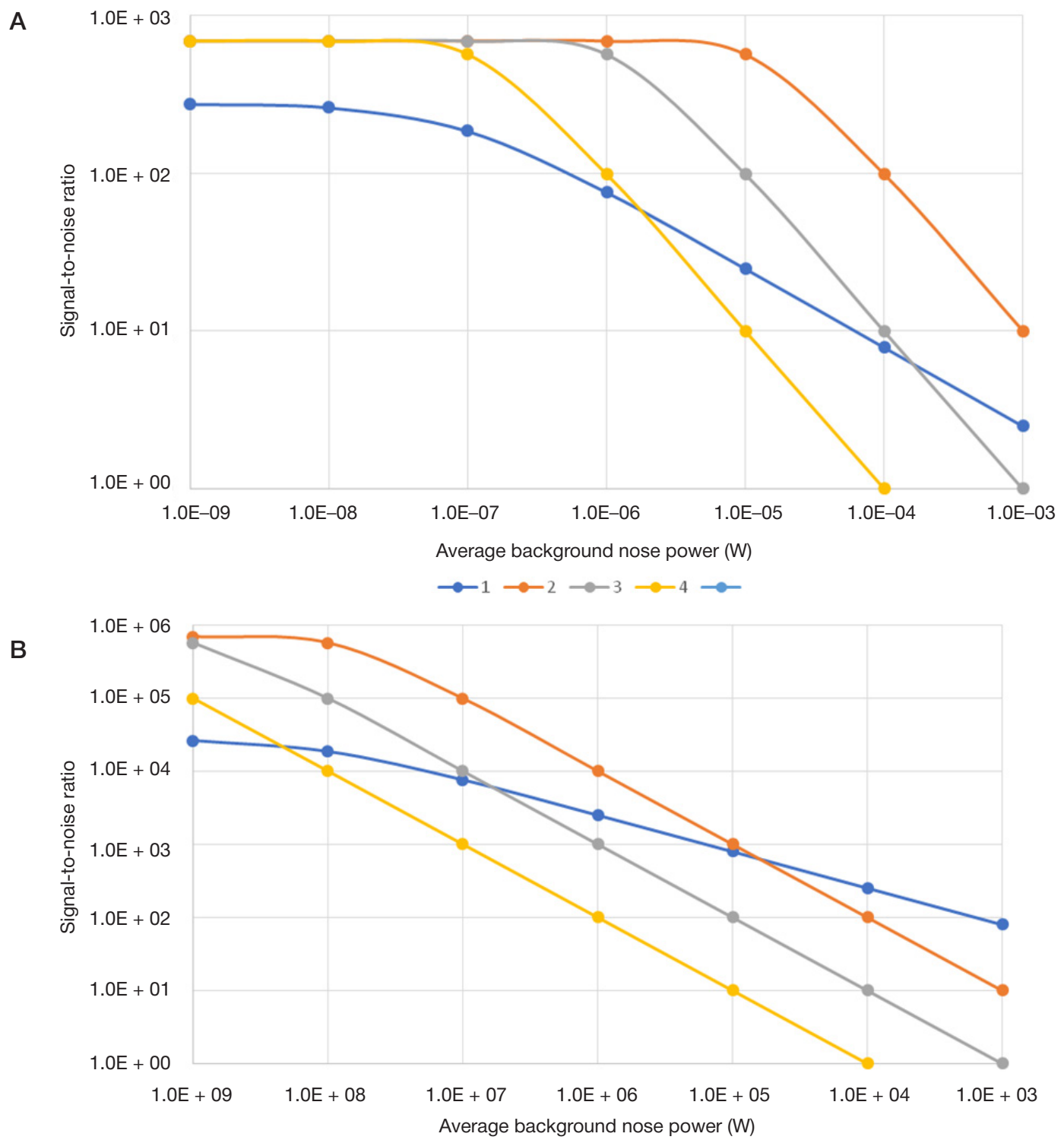

Fig. 1. Dependency of the signal-to-noise ratio of the receiver on the background noise power in the modulated excitation mode (1) and pulsed excitation mode (2) for a luminophore with an excited-state lifetime of $1 \mathrm{~ns}(2), 10 \mathrm{~ns}$ (3), and $100 \mathrm{~ns}$ (4). A. Signal accumulation times is $1 \mathrm{~ms}$, the average power of the fluorescent signal is $1 \mathrm{nW}$, the typical frequency of background fluctuations is $100 \mathrm{~Hz}$. B. Signal accumulation times is 1,000 ms, the average power of the fluorescent signal is $1 \mathrm{nW}$, the typical frequency of background fluctuations is $100 \mathrm{~Hz}$ 
where $d$ is the inverse duty cycle of excitation pulses. The pulse repetition rate $f_{\text {ex }}$ is determined by the requirements for the operational speed of the device and is limited by the excitedstate lifetime $\tau_{\text {lum }}$ of the used fluorophore. If the task is to obtain information about $\tau_{\text {lum }}$, then the duration of the excitation pulse $\tau_{\text {ex }}$ must be significantly lower than $\tau_{\text {lum }}$. But generally, it can be comparable to $\tau_{\text {lum }}$, mitigating requirements for the upper bound frequency, which in this case is $f_{\mathrm{p}} \approx 1 / \tau_{\text {lum }}$ or $f_{\mathrm{p}}=d \cdot f_{\mathrm{ex}}$.

The excited-state lifetime of such fluorophores as organic dyes and quantum dots normally varies from 1 to 100 ns [48, 49]. Therefore, the upper bound frequency of the photosensor must fall within an interval between $\sim 0.01$ and $1 \mathrm{GHz}$. Under such conditions, the contribution of additional low-frequency noises $\triangle \operatorname{NEP}(f)$ is negligible in comparison with the total thermal noise of the amplifier. With that in mind, NEP and the signal-to-noise ratio of the photosensor operating in the pulsedmodulation mode can be described by the following equations:

$$
S / N=\frac{P_{\text {lum }}}{P_{\mathrm{n}}}=\frac{<P_{\mathrm{lum}}>\cdot S \cdot d}{\sqrt{8 \pi \kappa \mathrm{T} C_{\mathrm{p}} f_{\mathrm{p}}} \cdot \sqrt{f_{\mathrm{p}}}}=\frac{<P_{\mathrm{lum}}>\cdot S}{\sqrt{8 \pi \kappa \mathrm{T} C_{\mathrm{p}}} \cdot f_{\mathrm{ex}}}
$$

To account for the effects of background light with the average power $P_{\mathrm{bg}}$, the obtained formulas have to be corrected. In the modulated excitation mode, the effect of background light is indirect and manifests as an increase in shot noise. In the pulsed-excitation mode, the effect of background light shows as fluctuations of external illumination with the typical borderline frequency $f_{\text {bg }}$. Considering that, the signal-to-noise ratio in both excitation modes can be written as

$$
\begin{aligned}
& S / N=\frac{<P_{\text {lum }}>}{\left[\begin{array}{c}
2 \pi \kappa T C_{\mathrm{p}} \Delta f_{\mathrm{p}}{ }^{2} n / S^{2}+ \\
\left.e P_{\mathrm{bg}} \Delta f_{\mathrm{p} / 2 S}\right]^{0.5}
\end{array}\right.} \\
& S / N=\frac{<P_{\text {lum }}>}{\left[8 \pi \kappa T C_{\mathrm{p}} f_{\mathrm{ex}}{ }^{2} / S^{2}+\left(P_{\mathrm{bg}} \tau_{\text {lum }} f_{\mathrm{bg}}\right)^{2}\right]^{0.5}}
\end{aligned}
$$

The formulas (7) and (8) allow adequate comparison of signalto-noise ratios in pulsed and modulated excitation modes at the same operational speed of the device and the same average power of the fluorescence signal (and, therefore, the same average power of excitation light).

A

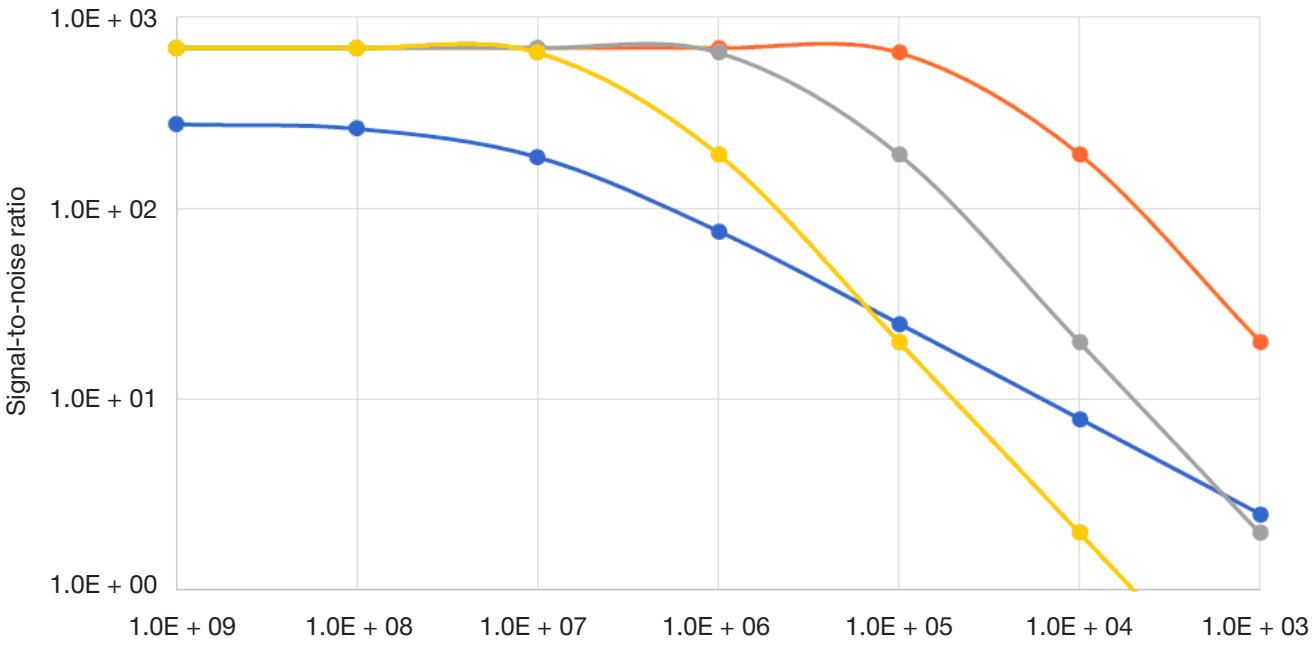

Average background nose power (W)

B

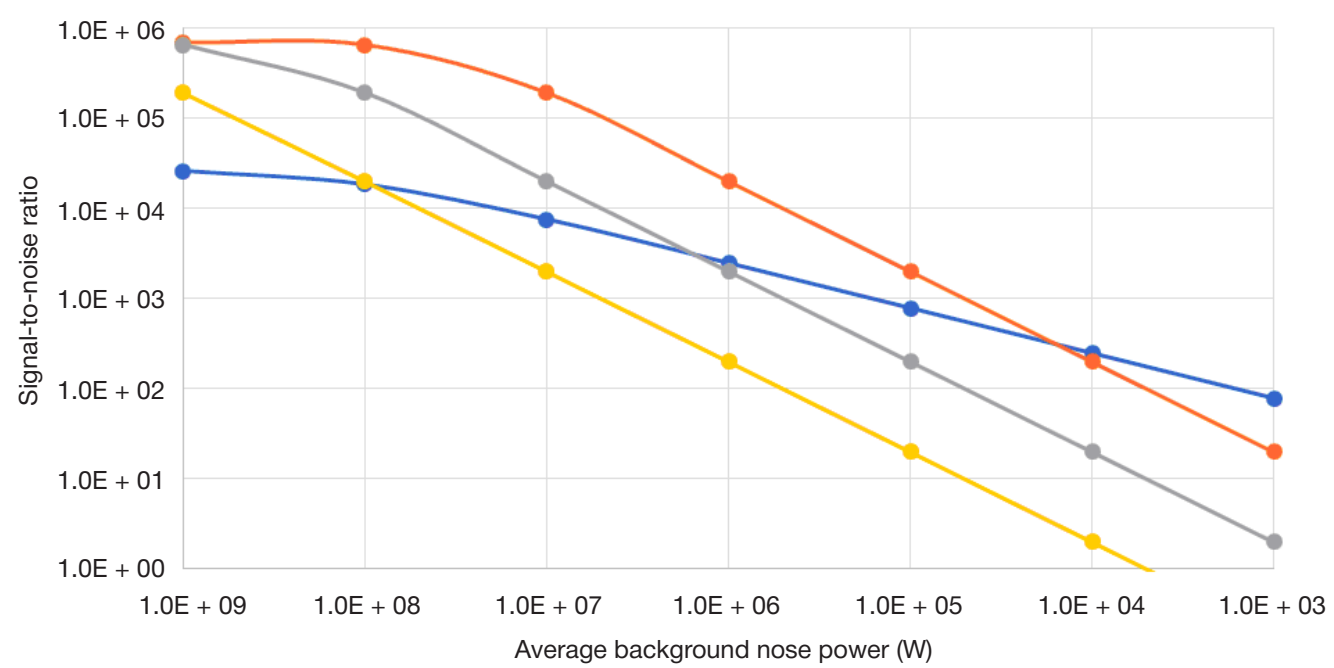

Fig. 2. Dependency of the signal-to-noise ratio of the receiver on the background noise power in the modulated excitation mode (1) and pulsed excitation mode (2) at typical frequencies of the background power fluctuation of $10 \mathrm{~Hz}(1), 100 \mathrm{~Hz}(2)$, and $1,000 \mathrm{~Hz}(4)$. A. Signal accumulation times is 1 ms, the average power of the fluorescent signal is $1 \mathrm{nW}$, the excited-state lifetime of the luminophore is $5 \mathrm{~ns}$. B. Signal accumulation times is 1,000 ms, the average power of the fluorescent signal is $1 \mathrm{nW}$, the excited-state lifetime of the luminophore is $5 \mathrm{~ns}$ 


\section{RESULTS}

Using the equations (7) and (8), we have analyzed the dependencies of the signal-to-noise ratio on different parameters, including the power and frequency of background light fluctuations, the operational speed of the photodetector and the excited-state lifetime of the fluorophore. For convenience, we constructed the curves shown in the figures below. Fig. 1A and $1 \mathrm{~B}$ feature curves representing dependencies of the signal-to-noise ratio on the power of background light for luminophores with different excited-state lifetimes. Figures 2A and $2 \mathrm{~B}$ show curves representing dependencies of the signalto-noise ratio on the power of background light at various typical frequencies of its fluctuations.

\section{DISCUSSION}

In the absence of background light, pulsed excitation of the fluorophore is preferable (Fig. 1A and 1B). In the presence of background light, pulsed excitation still should be opted for when fast results are needed and the selected fluorophore has an excited-state lifetime of less than $1 \mathrm{~ns}$.

At the same time, as the power of background light increases, the signal-to-noise ratio declines more slowly if pulse excitation is applied. Also, it is important to remember that the signal-to- noise ratio depends both on the excited-state lifetime of the fluorophore and the typical fluctuation frequencies of the background light power. Thus, for pulsed excitation the signal-to-noise ratio is lower than for modulated excitation if the excited-state lifetime of the luminophore is over 100 ns. A similar situation is observed when the average background light power exceeds $\sim 1 \mu \mathrm{W}$ and its typical fluctuation frequency is over $100 \mathrm{~Hz}$. Such conditions occur when scanning systems or artificial light sources are used [42, 43, 50], especially LED lamps [46]. The detection threshold of a photosensor operating in the modulated excitation mode at a properly selected modulation frequency will not depend on the excited-state lifetime of the selected luminophore or fluctuation frequencies of the background light power (Fig. 2A and 2B).

The excited-state lifetime of quantum dots normally falls within the range from 10 to $100 \mathrm{~ns}$. Thus, modulated excitation is a better choice if the task is to detect the ultralow quantities of semi-conductor quantum dots in the presence of background light with an average power of $>1 \mu \mathrm{W}$ given that signal accumulation time is least $100 \mathrm{~ms}$. Moreover, the sources of excitation light for the modulation-based method are cheaper and simpler in architecture than those generating very short (nano/pico) pulsed signals.

\section{CONCLUSIONS}

We have derived a mathematical expression for computing the signal-to-noise ratio for Si PIN photodiode photosensors operating in the pulsed and modulated excitation modes used for the induction of luminescence in the visible light spectra in the presence of background light. We have demonstrated that modulated excitation is preferable for luminescent CdSe/ZnS semi-conductor quantum dots given that signal accumulation time is at least $100 \mathrm{~ms}$ and the device is exposed to background light $>1 \mu \mathrm{W}$.

\section{References}

1. Moulick R, Udgaonkar JB. Identification and structural characterization of the precursor conformation of the prion protein which directly initiates misfolding and oligomerization. J Mol Biol. 2017; 429 (6): 886-899.

2. Chen $\mathrm{H}$, Rhoades E. Fluorescence characterization of denatured proteins. Curr Opin Struct Biol. 2008;18 (4): 516-524.

3. Hevekerl H, Tornmalm J, Widengren J. Fluorescence-based characterization of non-fluorescent transient states of tryptophan - prospects for protein conformation and interaction studies. Sci Rep. 2016; 6 (1): 35052.

4. Dramićanin T, Dramićanin M. Using fluorescence spectroscopy to diagnose breast cancer. Appl Mol Spectrosc to Curr Res Chem Biol Sci. 2016.

5. Sukhanova A, Even-Desrumeaux K, Kisserli A, et al. Oriented conjugates of single-domain antibodies and quantum dots: toward a new generation of ultrasmall diagnostic nanoprobes. Nanomedicine: NBM. 2012; 8 (4): 516-25.

6. Bilan R, Ametzazurra A, Brazhnik K, et al. Quantum-dot-based suspension microarray for multiplex detection of lung cancer markers: preclinical validation and comparison with the Luminex XMAP ${ }^{\circledR}$ system. Sci Rep. 2017; (7): 44668

7. Brazhnik K, Sokolova Z, Baryshnikova M, et al. Quantum dotbased lab-on-a-bead system for multiplexed detection of free and total prostate-specific antigens in clinical human serum samples. Nanomedicine: NBM. 2015; 11 (5): 1065-75.

8. Hafian $\mathrm{H}$, Sukhanova A, Turini $M$, et al. Multiphoton imaging of tumor biomarkers with conjugates of single-domain antibodies and quantum dots. Nanomedicine: NBM. 2014; 10 (8): 1701-9.

9. Sukhanova A, Susha AS, Bek A, et al. Nanocrystal-encoded fluorescent microbeads for proteomics: Antibody profiling and diagnostics of autoimmune diseases. Nano Lett. 2007; 7 (8): 2322-7.

10. Wessels $\mathrm{L}$, Raad $\mathrm{H}$. Recent advances in point of care diagnostic tools: a review. Am J Eng Appl Sci. 2016; 9 (4): 1088-1095.

11. Samokhvalov $P$, Artemyev M, Nabiev I. Basic principles and current trends in colloidal synthesis of highly luminescent semiconductor nanocrystals. Chem - A Eur J. 2013; 19 (5): 1534-1546.

12. Vokhmintcev KV, Samokhvalov PS, Nabiev I. Charge transfer and separation in photoexcited quantum dot-based systems. Nano Today. 2016; 11 (2): 189-211.

13. Resch-Genger U, Grabolle M, Cavaliere-Jaricot S, Nitschke R, Nann T. Quantum dots versus organic dyes as fluorescent labels. Nat Methods. 2008; 5 (9): 763-775.

14. Yu WW, Qu L, Guo W, Peng X. Experimental determination of the extinction coefficient of CdTe, CdSe, and CdS nanocrystals. Chem Mater. 2003; 15 (14): 2854-60.

15. Jasieniak J, Smith L, Van Embden J, Mulvaney P, Califano M. Reexamination of the size-dependent absorption properties of CdSe quantum dots. J Phys Chem C. 2009; 113 (45): 19468-74.

16. Krivenkov V, Samokhvalov P, Zvaigzne M, et al. Ligand-mediated photobrightening and photodarkening of $\mathrm{CdSe} / \mathrm{ZnS}$ quantum dot ensembles. J Phys Chem C. 2018; DOI: 10.1021/acs. jpcc.8b04544.

17. Ramos-Gomes, F, Bode J, Sukhanova A et al. Single- and twophoton imaging of human micrometastases and disseminated tumour cells with conjugates of nanobodies and quantum dots. Sci Rep. 2018; (8): 4595

18. Bonilla JC, Bozkurt F, Ansari S, Sozer N, Kokini JL. Applications of quantum dots in food Science and biology. Trends Food Sci Technol. 2016; (53): 75-89.

19. Collazuol G, Bisogni MG, Marcatili S, Piemonte C, Del Guerra A. Studies of silicon photomultipliers at cryogenic temperatures. Nucl Instruments Methods Phys Res Sect A Accel Spectrometers, Detect Assoc Equip. 2011; 628 (1): 389-92.

20. Takeuchi S, Kim J, Yamamoto Y, Hogue HH. Development of a high-quantum-efficiency single-photon counting system. Appl Phys Lett. 1999; 74 (8): 1063-5.

21. Moon S, Kim DY. Analog single-photon counter for high-speed 
scanning microscopy. Opt Express. 2008; 16 (18): 13990-14003.

22. Benninger RKP, Ashby WJ, Ring E a., Piston DW. A single-photon counting detector for increased sensitivity in two-photon laser scanning microscopy. Opt Lett. 2008; 33 (24): 2895-7.

23. Du B, Pang C, Wu D, et al. High-speed photon-counting laser ranging for broad range of distances. Sci Rep. 2018; 8 (1): 1-6.

24. Jang JY, Cho M. Image visualization of photon counting confocal microscopy using statistical estimation. Optik (Stuttg). 2016; 127 (2): 844-7.

25. Chen W, Wang X, Wang B, et al. Lock-in-photon-counting-based highly-sensitive and large-dynamic imaging system for continuouswave diffuse optical tomography. Biomed Opt Express. 2016; 7 (2): 499.

26. Boscher ND, Choquet P, Duday D, Verdier S. Advantages of a pulsed electrical excitation mode on the corrosion performance of organosilicon thin films deposited on aluminium foil by atmospheric pressure dielectric barrier discharge. Plasma Process Polym. 2010; 7 (2): 163-71.

27. Steen HB, Sqrensen OI. Pulse Modulation of the excitation light source boosts the sensitivity of an arc lamp-based flow cytometer. Cytometry. 1993; (14): 115-22.

28. Huang $C$, Lu X, Jiang Y, Wang X, Qiao Z, Fan W. Real-time characterization of FM-AM modulation in a high-power laser facility using an RF-photonics system and a denoising algorithm. Appl Opt. 2017; 56 (6): 1610-15.

29. Gak J, Miguez M, Bremermann M, Arnaud A. On the reduction of thermal and flicker noise in ENG signal recording amplifiers. Analog Integr Circuits Signal Process. 2008; 57 (1-2): 39-48.

30. De Marcellis A, Palange E, Giuliani R, Janneh M. Very high sensitivity electrically modulated Si-photodiode in photovoltaicmode as phase-sensitive detector of light power. Proc IEEE Sensors. 2014: 2014 December: 1115-7.

31. Ayat M, Karami MA, Mirzakuchaki S, Beheshti-Shirazi A. Design of multiple modulated frequency lock-in amplifier for tappingmode atomic force microscopy systems. IEEE Trans Instrum Meas. 2016; 65 (10): 2284-92.

32. Bhattacharyya S, Ahmed RN, Purkayastha BB, Bhattacharyya K. Implementation of digital lock-in amplifier. J Phys Conf Ser. 2016; 759 (1).

33. Datta S, Rajagopalan S, Lemke S, Joshi A. Balanced PIN-TIA photoreceiver with integrated $3 \mathrm{~dB}$ fiber coupler for distributed fiber optic sensors. 2014; 9098: 90980Y.

34. Angelini P, Blache F, Caillaud C, et al. High sensitivity SOA-PIN/TIA photoreceiver for $40 \mathrm{~Gb} / \mathrm{s}$ applications and beyond. Int J Microw Wirel Technol. 2016; 8 (03): 437-445.

35. Rahman SN, Hall D, Mei Z, Lo Y-H. Integrated 1550 nm

\section{Литература}

1. Moulick R, Udgaonkar JB. Identification and structura characterization of the precursor conformation of the prion protein which directly initiates misfolding and oligomerization. J Mol Biol. 2017; 429 (6): 886-899.

2. Chen $\mathrm{H}$, Rhoades E. Fluorescence characterization of denatured proteins. Curr Opin Struct Biol. 2008:18 (4): 516-524.

3. Hevekerl H, Tornmalm J, Widengren J. Fluorescence-based characterization of non-fluorescent transient states of tryptophan - prospects for protein conformation and interaction studies. Sci Rep. 2016; 6 (1): 35052.

4. Dramićanin T, Dramićanin M. Using fluorescence spectroscopy to diagnose breast cancer. Appl Mol Spectrosc to Curr Res Chem Biol Sci. 2016.

5. Sukhanova A, Even-Desrumeaux K, Kisserli A, et al. Oriented conjugates of single-domain antibodies and quantum dots: toward a new generation of ultrasmall diagnostic nanoprobes. Nanomedicine: NBM. 2012; 8 (4): 516-25.

6. Bilan R, Ametzazurra A, Brazhnik K, et al. Quantum-dot-based suspension microarray for multiplex detection of lung cancer markers: preclinical validation and comparison with the Luminex XMAP ${ }^{\oplus}$ system. Sci Rep. 2017; (7): 44668

7. Brazhnik K, Sokolova Z, Baryshnikova M, et al. Quantum dot- photoreceiver with built-in amplification and feedback mechanisms. Opt Lett. 2013; 38 (20): 4166-9.

36. Cervantes FG, Livas J, Silverberg R, Buchanan E, Stebbins R. Characterization of photoreceivers for LISA. Class Quantum Gravity. 2011; 28 (9).

37. M A, Gregory H. Photodetection. In: Michael Bass, editor. Handbook of Optics. McGraw-Hill , Inc.; 1994. 1664 p.

38. Lin TY, Green RJ, O'Connor PB. A low noise single-transistor transimpedance preamplifier for Fourier-transform mass spectrometry using a T feedback network. Rev Sci Instrum. 2012;83(9)

39. Jaquay JW. Designers Guide to: Instrumentation amplifiers. Exp Tech. 1977;2(2):40-43

40. Wai Chen. The Electrical Engineering Handbook. Elsevier Academic Press; 2004. 1228 p.

41. Vernotte F, Lantz E. Metrology and 1/f noise: Linear regressions and confidence intervals in flicker noise context. Metrologia. 2015; 52 (2): 222-37.

42. Sindhubala K, Vijayalakshmi B. Review jn impact of ambient light noise sources and applications in optical wireless communication using LED. International Journal of Applied Engineering Research. 2015; 10 (12): 31115-30.

43. Pham Q, Rachim V, An J, Chung W-Y. Ambient light rejection using a novel average voltage tracking in visible light communication system. Appl Sci. 2017; 7 (7): 670.

44. Shen Z, Thomas JJ, Siuzdak G, Blackledge RD. A case study on forensic polymer analysis by DIOS-MS: the suspect who gave us the SLIP. J Forensic Sci. 2004; 49 (5): 1028-35.

45. Cletus B, Olds W, Fredericks PM, Jaatinen E, Izake EL. Real-time detection of concealed chemical hazards under ambient light conditions using raman spectroscopy. J Forensic Sci. 2013; 58 (4): 1008-14

46. Kim T, Rylander M, Powers EJ, Grady WM, Arapostathis A. LED lamp flicker caused by interharmonics. Conf Rec - IEEE Instrum Meas Technol Conf. 2008: 1920-5.

47. Zumbahlen $\mathrm{H}$, editor. Linear Circuit Design Handbook. Newnes/ Elsevier; 2008. 960 p

48. Gong K, Martin JE, Shea-Rohwer LE, Lu P, Kelley DF. Radiative lifetimes of zincblende CdSe/CdS quantum dots. J Phys Chem C. 2015; 119 (4): 2231-8.

49. Berezin MMY, Achilefu S. Fluorescence lifetime measurements and biological imaging. Chem Rev. 2011; 110 (5): 2641-84.

50. Kovalenko B, Roskosky M, Freedman BA, Shuler MS. Effect of ambient light on near infrared spectroscopy. Trauma Treat. 2015; 911-6.

based lab-on-a-bead system for multiplexed detection of free and total prostate-specific antigens in clinical human serum samples. Nanomedicine: NBM. 2015; 11 (5): 1065-75

8. Hafian $\mathrm{H}$, Sukhanova $\mathrm{A}$, Turini $\mathrm{M}$, et al. Multiphoton imaging of tumor biomarkers with conjugates of single-domain antibodies and quantum dots. Nanomedicine: NBM. 2014; 10 (8): 1701-9.

9. Sukhanova A, Susha AS, Bek A, et al. Nanocrystal-encoded fluorescent microbeads for proteomics: Antibody profiling and diagnostics of autoimmune diseases. Nano Lett. 2007; 7 (8): 2322-7.

10. Wessels $L$, Raad $H$. Recent advances in point of care diagnostic tools: a review. Am J Eng Appl Sci. 2016; 9 (4): 1088-1095.

11. Samokhvalov P, Artemyev M, Nabiev I. Basic principles and current trends in colloidal synthesis of highly luminescent semiconductor nanocrystals. Chem - A Eur J. 2013; 19 (5): 1534-1546.

12. Vokhmintcev KV, Samokhvalov PS, Nabiev I. Charge transfer and separation in photoexcited quantum dot-based systems. Nano Today. 2016; 11 (2): 189-211.

13. Resch-Genger U, Grabolle M, Cavaliere-Jaricot S, Nitschke R, Nann T. Quantum dots versus organic dyes as fluorescent labels. Nat Methods. 2008; 5 (9): 763-775.

14. Yu WW, Qu L, Guo W, Peng X. Experimental determination of 
the extinction coefficient of CdTe, CdSe, and CdS nanocrystals. Chem Mater. 2003; 15 (14): 2854-60.

15. Jasieniak J, Smith L, Van Embden J, Mulvaney P, Califano M. Reexamination of the size-dependent absorption properties of CdSe quantum dots. J Phys Chem C. 2009; 113 (45): 19468-74.

16. Krivenkov V, Samokhvalov P, Zvaigzne M, et al. Ligand-mediated photobrightening and photodarkening of CdSe/ZnS quantum dot ensembles. J Phys Chem C. 2018; DOI: 10.1021/acs. jpcc.8b04544.

17. Ramos-Gomes, F, Bode J, Sukhanova A et al. Single- and twophoton imaging of human micrometastases and disseminated tumour cells with conjugates of nanobodies and quantum dots. Sci Rep. 2018; (8): 4595.

18. Bonilla JC, Bozkurt F, Ansari S, Sozer N, Kokini JL. Applications of quantum dots in food Science and biology. Trends Food Sci Technol. 2016; (53): 75-89.

19. Collazuol G, Bisogni MG, Marcatili S, Piemonte C, Del Guerra A. Studies of silicon photomultipliers at cryogenic temperatures. Nucl Instruments Methods Phys Res Sect A Accel Spectrometers, Detect Assoc Equip. 2011; 628 (1): 389-92.

20. Takeuchi S, Kim J, Yamamoto Y, Hogue HH. Development of a high-quantum-efficiency single-photon counting system. Appl Phys Lett. 1999; 74 (8): 1063-5.

21. Moon S, Kim DY. Analog single-photon counter for high-speed scanning microscopy. Opt Express. 2008; 16 (18): 13990-14003.

22. Benninger RKP, Ashby WJ, Ring E a., Piston DW. A single-photon counting detector for increased sensitivity in two-photon laser scanning microscopy. Opt Lett. 2008; 33 (24): 2895-7.

23. Du B, Pang C, Wu D, et al. High-speed photon-counting laser ranging for broad range of distances. Sci Rep. 2018; 8 (1): 1-6.

24. Jang JY, Cho M. Image visualization of photon counting confoca microscopy using statistical estimation. Optik (Stuttg). 2016; 127 (2): 844-7.

25. Chen W, Wang X, Wang B, et al. Lock-in-photon-countingbased highly-sensitive and large-dynamic imaging system for continuous-wave diffuse optical tomography. Biomed Opt Express. 2016; 7 (2): 499.

26. Boscher ND, Choquet P, Duday D, Verdier S. Advantages of a pulsed electrical excitation mode on the corrosion performance of organosilicon thin films deposited on aluminium foil by atmospheric pressure dielectric barrier discharge. Plasma Process Polym. 2010; 7 (2): 163-71.

27. Steen HB, Sqrensen OI. Pulse Modulation of the excitation light source boosts the sensitivity of an arc lamp-based flow cytometer. Cytometry. 1993; (14): 115-22.

28. Huang C, Lu X, Jiang Y, Wang X, Qiao Z, Fan W. Real-time characterization of FM-AM modulation in a high-power laser facility using an RF-photonics system and a denoising algorithm. Appl Opt. 2017; 56 (6): 1610-15.

29. Gak J, Miguez M, Bremermann M, Arnaud A. On the reduction of thermal and flicker noise in ENG signal recording amplifiers. Analog Integr Circuits Signal Process. 2008; 57 (1-2): 39-48.

30. De Marcellis A, Palange E, Giuliani R, Janneh M. Very high sensitivity electrically modulated Si-photodiode in photovoltaicmode as phase-sensitive detector of light power. Proc IEEE Sensors. 2014: 2014 December: 1115-7.

31. Ayat M, Karami MA, Mirzakuchaki S, Beheshti-Shirazi A. Design of multiple modulated frequency lock-in amplifier for tapping- mode atomic force microscopy systems. IEEE Trans Instrum Meas. 2016; 65 (10): 2284-92.

32. Bhattacharyya S, Ahmed RN, Purkayastha BB, Bhattacharyya K Implementation of digital lock-in amplifier. J Phys Conf Ser. 2016; 759 (1).

33. Datta S, Rajagopalan S, Lemke S, Joshi A. Balanced PIN-TIA photoreceiver with integrated $3 \mathrm{~dB}$ fiber coupler for distributed fiber optic sensors. 2014; 9098: 90980Y.

34. Angelini P, Blache F, Caillaud C, et al. High sensitivity SOA-PIN/ TIA photoreceiver for $40 \mathrm{~Gb} / \mathrm{s}$ applications and beyond. Int J Microw Wirel Technol. 2016; 8 (03): 437-445.

35. Rahman SN, Hall D, Mei Z, Lo Y-H. Integrated $1550 \mathrm{~nm}$ photoreceiver with built-in amplification and feedback mechanisms. Opt Lett. 2013; 38 (20): 4166-9.

36. Cervantes FG, Livas J, Silverberg R, Buchanan E, Stebbins R. Characterization of photoreceivers for LISA. Class Quantum Gravity. 2011; 28 (9).

37. M A, Gregory H. Photodetection. In: Michael Bass, editor. Handbook of Optics. McGraw-Hill , Inc.; 1994. 1664 p.

38. Lin TY, Green RJ, O'Connor PB. A low noise single-transistor transimpedance preamplifier for Fourier-transform mass spectrometry using a T feedback network. Rev Sci Instrum. 2012;83(9).

39. Jaquay JW. Designers Guide to: Instrumentation amplifiers. Exp Tech. 1977:2(2):40-43

40. Wai Chen. The Electrical Engineering Handbook. Elsevier Academic Press; 2004. 1228 p.

41. Vernotte F, Lantz E. Metrology and 1/f noise: Linear regressions and confidence intervals in flicker noise context. Metrologia. 2015; 52 (2): 222-37.

42. Sindhubala K, Vijayalakshmi B. Review jn impact of ambient light noise sources and applications in optical wireless communication using LED. International Journal of Applied Engineering Research. 2015; 10 (12): 31115-30.

43. Pham Q, Rachim V, An J, Chung W-Y. Ambient light rejection using a novel average voltage tracking in visible light communication system. Appl Sci. 2017; 7 (7): 670

44. Shen Z, Thomas JJ, Siuzdak G, Blackledge RD. A case study on forensic polymer analysis by DIOS-MS: the suspect who gave us the SLIP. J Forensic Sci. 2004; 49 (5): 1028-35.

45. Cletus B, Olds W, Fredericks PM, Jaatinen E, Izake EL. Real-time detection of concealed chemical hazards under ambient light conditions using raman spectroscopy. J Forensic Sci. 2013; 58 (4): 1008-14.

46. Kim T, Rylander M, Powers EJ, Grady WM, Arapostathis A. LED lamp flicker caused by interharmonics. Conf Rec - IEEE Instrum Meas Technol Conf. 2008: 1920-5.

47. Zumbahlen $\mathrm{H}$, editor. Linear Circuit Design Handbook. Newnes/ Elsevier; 2008. $960 \mathrm{p}$

48. Gong K, Martin JE, Shea-Rohwer LE, Lu P, Kelley DF. Radiative lifetimes of zincblende CdSe/CdS quantum dots. J Phys Chem C. 2015; 119 (4): 2231-8.

49. Berezin MMY, Achilefu S. Fluorescence lifetime measurements and biological imaging. Chem Rev. 2011; 110 (5): 2641-84.

50. Kovalenko B, Roskosky M, Freedman BA, Shuler MS. Effect of ambient light on near infrared spectroscopy. Trauma Treat. 2015; 911-6. 